\title{
THE SCIENCE OF JUDICIAL PSYCHOLOGY
}

\section{P. TĂRCHILĂ}

\section{Petru TĂRCHILĂ}

Faculty of Humanities

„Aurel Vlaicu” University of Arad

Corespondence: Complex Universitar M (Micălaca), str. Elena Drăgoi, nr. 2, 310330, Arad

E-mail: ijjs@univagora.ro

ABSTRACT: Judicial psychology is the science that analyzes and tries to understand the criminal phenomenon in general and its determinant factor in particular, by the complexity of factors that generate it and by the diversity of its forms of manifestation. Although the determining factor of criminal behavior is always subjective being generated by the psychic of the offender, this aspect must be correlated with the context in which it manifests itself: social, economic, cultural context etc. Judicial psychology investigates the behavior of the individual in all its aspects, seeking a scientific explanation of the mechanisms and factors enhancing criminal favors, thus enabling the identification of the preventive measures to be taken to reduce the categories of offenses. It studies the psychobehavioral profile of the offender, identifying the causes that determined its behavior in order to take preventive measures.

The domain of judicial psychology is mainly deviance, conduct that departs from the moral or legal norms that are dominant in a given culture. The object of judicial psychology is the criminal act, correlated with the psychosocial characteristics of the participants in the judicial action (offender, victim, witness, investigator, magistrate, lawyer, civil party, educator, etc.). The science of judicial psychology also analyzes how these characteristics appear and manifest themselves in concrete and special conditions of their interaction in three phases of the criminal act: the pre-criminal phase, the actual criminal phase and the post-criminal phase.

KEYWORDS: judicial psychology, offender, victim, pre-criminal phase, postcriminal phase, criminal offense, psycho-behavioral profile of the offende

\section{THE SCIENCE OF JUDICIAL PSYCHOLOGY.}

Judicial psychology is the science that analyzes and tries to understand the criminal phenomenon in general and its determinant factor in particular, by the complexity of factors that generate it and by the diversity of its forms of manifestation. ${ }^{1}$ Although the determining factor of criminal behavior is always subjective being generated by the psychic of the offender, this aspect must be correlated with the context in which it manifests itself: social, economic, cultural context etc. Judicial psychology investigates the behavior of the individual in all its aspects, seeking a scientific explanation of the mechanisms and factors enhancing criminal favors, thus enabling the identification of the preventive measures to be taken to reduce the categories of offenses. It studies the psycho-behavioral profile of the offender,

\footnotetext{
${ }^{1}$ See,Butoi,T.,Psihologie judiciară,Ediţia a II-a,Editura Fundaţiei România de Mâine București 2004,pag.221.
} 


\section{Petru Tărchilă}

identifying the causes that determined its behavior in order to take preventive measures. As a stand-alone science, judicial psychology analyzes human personality, following how it manifests and acts in family and society.

The domain of judicial psychology is mainly deviance, conduct that departs from the moral or legal norms that are dominant in a given culture. The object of judicial psychology is the criminal act, correlated with the complex study and analysis of human behavior before, during and after the use of the offense. Judicial psychology studies the psychosocial characteristics of the participants in the legal action (offender, victim, witness, investigator, magistrate, lawyer, civil party, educator, etc.), how these characteristics appear and manifest in concrete and special conditions of their interaction in the three phases of the criminal act: the pre-criminal phase, the actual criminal phase and the post-criminal phase. It is important to specify the objectives of judicial psychology, taking into account, first of all, those who will benefit from and effectively use the results of research in this field.

Judicial psychology is primarily addressed to justice specialists who, by their nature, deal with people involved in criminal cases and whose decisions can influence their destiny. The act of justice can not be understood and accepted outside the desiderate that governs the intention of the legislator, namely, finding out the truth. Judicial psychology imposes a series of requirements without which the act of justice remains a sterile, technicalist exercise, lacking credibility and force. In terms of methods, judicial psychology as an applied part of general and social psychology has taken over most elements from their conceptual framework, using techniques and investigative tools specific to these disciplines: observation, experiment, psychosocial investigation, and judicial investigation as specific methods based on questionnaires and interviews), the biographical method, the activity analysis method, the opinion poll, etc. The system of categories with which judicial psychology operates belongs to general and social psychology, but also to other related disciplines, thus having an interdisciplinary character. In organizing and conducting his theoretical and practical approach, judicial psychology also uses notions from other psychological disciplines such as experimental psychology, differential psychology, cognitive psychology, psychophysiology, medical psychology, psychopathology, military psychology, psychology of conduct, etc. The theoretical approach of judicial psychology consists of: organizing, developing and improving an operative conceptual system; the validation of conceptual theoretical and explanatory models elaborated by other branches of psychology, following their testing on the specific field of judicial activity; elaboration of theoretical and explanatory models regarding the etiology of some psychic phenomena in the judiciary field, etc.

The practical approach of judicial psychology presupposes: elaboration of a specific methodology for investigation-research of the psychic reality in the judicial field and highlighting the legal phenomena of psychological phenomena specific to this field; providing specialized judicial staff with data, relevant and useful information about the psychic reality of the judiciary in order to establish the truth; the development of psycho-social programs to prevent crimes and recidivism; developing strategies for educational therapy for criminals; elaboration of recovery programs for socio-professional reintegration of offenders; the provision of psychological assistance, materialized in the specialized expertise offered to both the judiciary and the offenders, etc.

\section{ANALYSIS OF THE CRIMINAL ACT AND ITS CAUSAL COMPLEXITY}


In order to analyze the criminal phenomenon in its vast complexity, it is necessary to study disciplines such as: criminology, judicial psychology, judicial sociology, criminal biology, legal medicine, criminal psychiatry, criminal anthropology, criminal statistics etc. Although it is a social phenomenon, criminality must be investigated individually, as an act committed by a concrete person in a concrete situation. It is a human action, determined by certain psychological elements, needs, tendencies, motives, goals, etc. A coherent vision of the dynamics and interaction of the elements of the whole set of factors that contribute to the production of the criminal act can only provide a systemic conception of the conduct and psycho-behavioral manifestations.

The factors underpinning the psycho-biological, psycho-social, and psycho-moral theories, taken separately, can not adequately explain the origin of the phenomenon and the criminal behavior. This presupposes the development of a theoretical-scientific and methodological system with integrating possibilities and generalizers for the concrete reality. In Romania, the evolution of the criminal phenomenon is a consequence of the impact of the serious economic and social problems characteristic to the transition period, as well as the crisis of authority that the institutions crossed. Lack of legislation and overload of the criminal justice system, correlated with staff shortages and logistics, have limited the effect of preventive and repressive measures. Elements of organized crime have emerged and developed most rapidly in the economic and financial sphere given the high rate of profit and the low degree of risk incurred.

To explain the mechanism of the occurrence and the dynamics of the criminal phenomenon, it is necessary to start from the concept of connection that involves the interaction of objects and phenomena, the correlation of the subsystems into the system and the systems in the context. In accordance with the principle of connection, the origin and dynamics of the criminal phenomenon can not be the result of a single factor or of several factors, but only of the interactions between them, which gives it the configuration and which has an objective character.

The difficulty of the theoretical approach and the practical investigation of the etiogenesis of the criminal phenomenon derives precisely from the impediments that arise in the discovery of the types of relations that act specifically in this field. The use of the "possibility and reality" categories mediates the surprise of the mechanism of the synthesis between continuous and discontinuous in the transition from one state to another in the process of determining the criminal phenomenon. Unlike reality, the possibility designates the totality of virtual states through which the criminal phenomenon can pass, but for which there are still insufficient conditions. At this level, it is necessary to locate the true prevention, which must precisely prevent or eliminate the appearance and influence of conditions that facilitate the passage from the realm to the real one in the case of a concrete crime.

The timely and effective intervention is strongly conditioned by the understanding that the dynamics of internal and external interactions, current or prospective, of biopsychosocial factors marked by criminogenic influences determine a wide range of present or future possibilities in the occurrence and manifestation of the criminal phenomenon.

The boundaries between the possible and the impossible crime are relative, because the evolution of the manifestation states has a concrete character and is the expression of the internal content and the variability of the range that favors or suppresses some directions. It 


\section{Petru Tărchilă}

should also be emphasized that if some directions are part of the system's essence, others are cantonized to its accidental aspects.

The former are necessary directions and manifest as dominant tendencies, while the other are random and do not depend on the internal and stable conditions, but on the nonessential variable conditions. The necessity of the criminal phenomenon is the way of existence or manifestation of criminogenic states, properties, relationships or tendencies, circumscribed at the level of biopsychosocial factors, taken in their interaction, deriving from their internal nature and, under constant conditions, unfold as inevitably in - a certain wellspecified way.

Opposite to necessity, occurrence is the way of existence or manifestation of criminogenic states, properties, relations or tendencies located at the same level that derive from the peripheral or external factors and are characterized by variability and inconsistency, whether or not they succeed is done in one way or another, without affecting the essence of the system. Necessity and occurrence are not absolute, but relative, so that in a particular report or given circumstances, what is necessary may be incidental, in another relation or under other conditions. Thus, for example, theft committed by a person who has not been offered the chance of a job and in his conception does not have other possibilities of honest gain, seems necessary, whereas in the conditions of a stable work place can be considered a coincidence.

Reality, possibility and impossibility, along with necessity and chance, are categories that express qualitative states of the criminal phenomenon, its existence also involves quantitative determinations found in the concept of probability. In this case, it refers to the possibilities of becoming a criminal offense, to the extent and frequency of conditions conducive to the transition from a virtual state to a real one, to the chances of committing a criminal offense. Probability is found in the frequency equation as a ratio between the number of actual offenses and the total number of possible cases. Probability has meaning and value only in the case of casual offenses, because there are at least two possibilities: to be committed or not, to be committed in one form or another. Probability gains increasing significance and importance, as criminological prognosis shapes its place and role in criminal prophylaxis.

The causal relationship, as a particular form of determining the criminal phenomenon with its proximal genres and concrete facts of manifestation, expresses a genetic relationship and is considered as a link independent of the will of man between two subsystems or elements of the same system that succeed; one provoking the other one. The phenomenon that precedes and causes the production of another phenomenon is called a cause and which, from a criminological perspective, has the interaction of the biopsychosocial factors that necessarily determine the offense. Cause is the necessary condition without which a certain behavior would not manifest and at the same time precedes the effect being invariably followed by the same effect.

The effect is the phenomenon or process that succeeds the cause and whose production is determined by it. Between cause and effect, a need report is established. The constant of this report is marked by conditions. Causes produce the same effects only if they act under the same conditions, just as the variability of the conditions mediates the variability of effects in relation to the action of the same causes. 
The interaction between cause and effect is complex. ${ }^{2}$ On the one hand, the phenomena are, at the same time, in different ratios, both causes and effects, and on the other hand, several causes interact in the production of effects, which in turn act in close connection to various conditions.

Once it appears, the effect can have an active role on the cause that generated it, influencing it favorably or unfavorably. Conditions are a complex of phenomena that can not in themselves generate criminal behaviors but which, accompanying time and space cause and influence them, assureing a certain evolution. Conditions may be necessary, incidental, sufficiently necessary, insufficiently necessary.

The conditions accompanying the action of the cause, mark their manifestation by hurrying or slowing, stimulating or hindering the appearance of a certain effect. The difficulty of revealing causal relationships in determining the criminal phenomenon derives from the fact that they correlate with the entire network of other relationships present in its structure and dynamics. In order to facilitate their conduction, particularly at the level of concrete criminal offenses, theoreticians and practitioners are concerned with the isolation of causal relationships in the universe of possible relationships, with particular reference to the motives and relationships on which the subjective side of the crimes under consideration are based.

\section{ANALYSIS OF THE CRIMINAL PHENOMENON}

For the correct interpretation of criminal behavior, the three phases of the offense must be taken into account, namely the pre-criminal phase, the actual criminal phase and the postcriminal phase. The pre-criminal situation is a set of circumstances outside the offender's personality, which precedes the offense. This situation involves two elements:

a) the event that determines the occurrence of the criminal idea, and

b) the circumstances in which the offense is being prepared and is being carried out

In committing a crime, its author participates with his whole being, mobilizing his potential otivational and cognitive-emotional potential. The enforcement of the decision to commit the offense is preceded by a series of processes of analysis and synthesis, the fight of motives, deliberation and enforceable acts deeply engaging, in all its complexity, the personality of the offender.

Until the decision to commit the offense is made, the offender's psyche is dominated by the perception and processing of triggering motivational information whose polarity is structured according to the pattern of related-evolutive syntheses, serving the deliberations on the mobile behavior of criminal behavior. As an initial step in the formation of the criminal behavioral mobile, there are the needs whose antisocial orientation is of fundamental importance, because of their perception of the external situation.

From a psychological point of view, the needs are manifested in the individual's consciousness as a mobile of possible behavior, and in case of a contest of circumstances, they can determine the decision making for committing the offense. The outcome of the deliberation process depends largely on the degree of intensity of the antisocial orientation of the offender`s personality. In the pre-infraction phase the subjective premises of committing the act are determined both by the psychic predispositions of the perpetrator and by the favorable circumstances with triggering valences. This stage is characterized by intense inward consumption, reaching even a high degree of excitement, the psychological issue

\footnotetext{
${ }^{2}$ SeeTănăsescu,C.,Psihologie judiciară,Editura All,Bucureşti 2009,pag.155.
} 


\section{Petru Tărchilă}

being focused on both the risk coefficient and the stake placed in the game. In the deliberative process, motivational, value, moral, emotional, and material criteria come into play.

The ability to project and anticipate consequences influences the decision-making. The processes of analyzing and synthesizing data about the crime scene and structuring them in a range of concrete variants of action (transitive behavior of choosing the optimal variant) are triggered in the second phase of the act, the actual crime scene.

The action plan in its deployment (time of execution, succession of stages, means of realization, etc.) is mentally represented. Once the decision to commit the offense has been finalized, the imaginative side of the offense is supported by concrete preparatory actions. Thus, if during the deliberation stage the offender`s behavior is of expectation, after the decision has been made, it is characterized by activism, the execution of the preparatory acts presupposes the appeal to the means of assistance, the tools, the contacting of accomplices, the gathering of information, the supervision of the objective.

The result of this behavior may be, as the case may be, the materialization of the decision to commit the act by achieving the optimal conditions for its success, either the discontinuance, the delay, the expectation of favorable conditions and circumstances. The transition to accomplishment of the act is associated with experiencing intense emotional states. Fear of unpredictability, time crises, objects, beings or phenomena perceived during the act of committing the deed (breaking instruments, weapons, victim, witnesses, space-time context of the deed, etc.), depending on their physical and chemical properties , shape, size, color, spatial mood, etc.) amplify these emotional states. Lack of control over behavior during operation, a feature of normal activity can generate a series of errors, loopholes (loss of personal belongings at the crime scene, forgetting of offending objects or omission of deleting some categories of traces, giving up the glove port, various injuries, etc.), which, after being exploited, will contribute to the identification of the author.

The characteristic feature of the perpetrator's psychology after committing the deed is the tendency to defend itself, to evade identification, accusation and sanction. The postinfractional phase has a very varied configuration, its content is largely determined by the way the previous phase has unfolded. The behavior of the offender at this stage is reflexiveaction, his whole psychic activity being marked by the panoramic view of what happened at the scene. Practice has demonstrated in this respect the existence of a register of strategies to counteract the identification and prosecution of authors. In this respect, a number of criminals create alibis to convince the authorities that it was impossible for them to have committed the deed.

The strategy used is, as a rule, to move away from the crime scene in due time and to appear as soon as possible in another place where, through various actions, it seeks to be remembered to create evidence, relying on that after a certain period it will be difficult to accurately determine the succession of the two events in time. Otherwise, the offender appears around the place where the investigations are conducted, seeking to obtain information about their conduct, and subsequently acting through denunciations, anonymous notices, changes in the field of action, removal of evidence, home displacement, hospital admission, or committing small actions to be arrested.

All these actions are aimed at confusing the ongoing investigation and, implicitly, its identification. Running from the place where a crime has occurred and the concern to get an "alibi" is not always a clue of guilt. In order to determine the circumstances in which the deed 
was committed, people of different qualities will be heard ${ }^{3}$. There are cases when people who happened to have witnessed or found a crime, do not stay at the scene, to be suspected or quoted as a witness. Such behavior is typical of the recidivists, who, as a result of their criminal history, would be slightly blamed. In pursuing the purpose, offenders do not hesitate to use any means that could help them: lying, perfidy, various attitudes, seeking to inspire sympathy for their injustice or for the situation in which they have become "circumspect". When these strategies are unsuccessful, some offenders show arrogance to the investigator or sometimes resort to, even intimidating him.

The processing of information about the events that have occurred causes the emergence of an exciting focal point with an inhibitory effect on the other areas, especially those involved in the processing of those events that are not related to the offense, and acts at the behavioral level according to the law defensive dominance. The offender has a defensive attitude both during the commission of the offense and after the arrest, during the investigation and trial, sometimes even during the execution of the punishment. When the offender was included in the suspect circle and is invited for hearings, his behavior continues to be characterized by the simulation tendency. It has a defensive attitude, ranging from small distortions to systematic attempts to improve its procedural condition.

The offender adopts different tactical positions determined not only by his degree of guilt but also by his position towards the investigator. If the offender feels that he or she dominates the investigator (either in the capacity to argue or in the evidence he has on his guilt), he will be extremely cautious in what he relates and will not give up his position unless there is evidence strong. If he realizes the superiority of the investigator, then his resistance decreases and the defensive dominance will only manifest through some adjustments to the statements he makes. Most offenders are inconsistent in depositions, recognize a party at first, then deny fiercely, return to what has been declared, in the end to make a confession, but also incomplete.

Among the circumstances that may constitute attenuating circumstances stipulated in the Criminal Code (Article 74, letter c), there is also the one regarding the perpetrator's attitude after committing the offense. This attitude may consist in presenting willingly to the criminal investigation bodies, in sincere attitude throughout the trial, recognizing from the beginning that he committed the deed and stating precisely the circumstances surrounding it. Everything can be corroborated with the traces discovered at the scene, the preference for certain objects, the traitor's interest in removing the traces, which, from the initial stage, helps the judiciary to bring the perpetrator into a particular group ${ }^{4}$.

Once the offender has been identified and receives legal punishment, it would be ideal to have a psycho-behavioral profile in place to implement an appropriate corrective program. Difficulties in this area lie in the fact that the diagnosis of each case is laborious, requiring the participation of several specialists (psychologists, magistrates, sociologists, criminologists, lawyers, etc.). ${ }^{5}$ The most accurate diagnosis of the psycho-behavioral profile of the offenders, the most accurate identification of the causes that determined their antisocial behavior, would be essential requirements for shaping the therapeutic-recuperatory programs within the correctional institutions, impacting on their reinsertion and social reintegration.

\footnotetext{
${ }^{3}$ Elena Ana Nechita, Metodologia investigării infracţiunilor, Ed. PRO Univeristaria, 2012, p.115.

${ }^{4}$ Elena-Ana Nechita, Criminalistică, edition II, revision, Ed. PRO Univeristaria, 2009, p.145

See,Tănăsescu,C.,Psihologie judiciară,Editura All,Bucureşti 2009 ,pag.162.
} 


\section{Petru Tărchilă}

\section{CONCLUSIONS:}

Judicial psychology is the science that analyzes and tries to understand the criminal phenomenon in general and its determinant factor in particular, by the complexity of factors that generate it and by the diversity of its forms of manifestation. Although the determining factor of criminal behavior is always subjective being generated by the psychic of the offender, this aspect must be correlated with the context in which it manifests itself: social, economic, cultural context etc.

Judicial psychology investigates the behavior of the individual in all its aspects, seeking a scientific explanation of the mechanisms and factors enhancing criminal favors, thus enabling the identification of the preventive measures to be taken to reduce the categories of offenses. It studies the psycho-behavioral profile of the offender, identifying the causes that determined its behavior in order to take preventive measures. As a stand-alone science, judicial psychology analyzes human personality, following how it manifests and acts in family and society.

The domain of judicial psychology is mainly deviance, conduct that departs from the moral or legal norms that are dominant in a given culture. The object of judicial psychology is the criminal act, correlated with the complex study and analysis of human behavior before, during and after the use of the offense. Judicial psychology studies the psychosocial characteristics of the participants in the legal action (offender, victim, witness, investigator, magistrate, lawyer, civil party, educator, etc.), how these characteristics appear and manifest in concrete and special conditions of their interaction in the three phases of the criminal act: the pre-criminal phase, the actual criminal phase and the post-criminal phase.

In order to analyze the criminal phenomenon in its vast complexity, it is necessary to study disciplines such as: criminology, judicial psychology, judicial sociology, criminal biology, legal medicine, criminal psychiatry, criminal anthropology, criminal statistics etc. Although it is a social phenomenon, criminality must be investigated individually, as an act committed by a concrete person in a concrete situation. It is a human action, determined by certain psychological elements, needs, tendencies, motives, goals, etc. A coherent vision of the dynamics and interaction of the elements of the whole set of factors that contribute to the production of the criminal act can only provide a systemic conception of the conduct and psycho-behavioral manifestations.

The factors underpinning the psycho-biological, psycho-social, and psycho-moral theories, taken separately, can not adequately explain the origin of the phenomenon and the criminal behavior. This presupposes the development of a theoretical-scientific and methodological system with integrating possibilities and generalizers for the concrete reality. In Romania, the evolution of the criminal phenomenon is a consequence of the impact of the serious economic and social problems characteristic to the transition period, as well as the crisis of authority that the institutions crossed. Lack of legislation and overload of the criminal justice system, correlated with staff shortages and logistics, have limited the effect of preventive and repressive measures.

For the correct interpretation of criminal behavior, the three phases of the offense must be taken into account, namely the pre-criminal phase, the actual criminal phase and the postcriminal phase. The pre-criminal situation is a set of circumstances outside the offender's personality, which precedes the offense. This situation involves two elements:

a) the event that determines the occurrence of the criminal idea, and

b) the circumstances in which the offense is being prepared and is being carried out 
In committing a crime, its author participates with his whole being, mobilizing his potential motivational and cognitive-emotional potential.

The enforcement of the decision to commit the offense is preceded by a series of processes of analysis and synthesis, the fight of motives, deliberation and enforceable acts deeply engaging, in all its complexity, the personality of the offender. Until the decision to commit the offense is made, the offender's psyche is dominated by the perception and processing of triggering motivational information whose polarity is structured according to the pattern of related-evolutive syntheses, serving the deliberations on the mobile behavior of criminal behavior.

As an initial step in the formation of the criminal behavioral mobile, there are the needs whose antisocial orientation is of fundamental importance, because of their perception of the external situation. From a psychological point of view, the needs are manifested in the individual's consciousness as a mobile of possible behavior, and in case of a contest of circumstances, they can determine the decision making for committing the offense. The outcome of the deliberation process depends largely on the degree of intensity of the antisocial orientation of the offender`s personality. In the pre-infraction phase the subjective premises of committing the act are determined both by the psychic predispositions of the perpetrator and by the favorable circumstances with triggering valences.

This stage is characterized by intense inward consumption, reaching even a high degree of excitement, the psychological issue being focused on both the risk coefficient and the stake placed in the game. In the deliberative process, motivational, value, moral, emotional, and material criteria come into play.

The ability to project and anticipate consequences influences the decision-making. The processes of analyzing and synthesizing data about the crime scene and structuring them in a range of concrete variants of action (transitive behavior of choosing the optimal variant) are triggered in the second phase of the act, the actual crime scene.

The action plan in its deployment (time of execution, succession of stages, means of realization, etc.) is mentally represented. Once the decision to commit the offense has been finalized, the imaginative side of the offense is supported by concrete preparatory actions. Thus, if during the deliberation stage the offender`s behavior is of expectation, after the decision has been made, it is characterized by activism, the execution of the preparatory acts presupposes the appeal to the means of assistance, the tools, the contacting of accomplices, the gathering of information, the supervision of the objective.

The result of this behavior may be, as the case may be, the materialization of the decision to commit the act by achieving the optimal conditions for its success, either the discontinuance, the delay, the expectation of favorable conditions and circumstances. The transition to accomplishment of the act is associated with experiencing intense emotional states. Fear of unpredictability, time crises, objects, beings or phenomena perceived during the act of committing the deed (breaking instruments, weapons, victim, witnesses, space-time context of the deed, etc.), depending on their physical and chemical properties, shape, size, color, spatial mood, etc.) amplify these emotional states.

\section{BIBLIOGRAPHY:}

1. Butoi,T., Psihologie judiciară, ediţia a II-a, Editura Fundaţiei România de Mâine Bucureşti 2004; 


\section{Petru Tărchilă}

2. Elena-Ana Nechita, Criminalistică. Tehnică şi tactică criminalistică, edition II, revision, Ed. PRO Univeristaria, 2009;

3. Elena Ana Nechita, Metodologia investigării infracţiunilor, Ed. PRO Univeristaria, 2012, p.115.

4. Tănăsescu, C., Psihologie judiciară, Editura All,Bucureşti, 2009;

5. Voica,A., Psihologie judiciară, Editura All Beck, Bucureşti, Bucureşti 2011;

6. Spineanu-Matei,O., Psihologia infractorului,Editura Trei, Bucureşti 2014. 